\title{
NUMERICAL SIMULATION AND CO-SIMULATION IN ANALYSIS OF MANIPULATORS' DYNAMICS
}

\begin{abstract}
Application of general purpose computing environments to analysis of manipulators' dynamics gives ability to select elastically the model structure and analysis algorithms, as well as full access to the intermediate results, however, it often requires introduction of various simplifications of the model under consideration. The alternative approach consists in application of the specialized software packages that allow the use of more sophisticated models, but at the cost of restricted access to the intermediate results as well as the limited range of possible modifications of models and solution algorithms. The authors focused on application of the co-simulation technique in analysis of manipulators' dynamics. Co-simulation consists in application of specialized software packages to formulation of the dynamic model. Next, the model is simulated with use of a general purpose computing environment and co-operating specialized software package. The authors used Matlab/Simulink computing environment and MD ADAMS software package. The paper presents comparison of results, problems of application, as well as remarks on educational applicability of manipulator dynamics analysis with use of the simulation and the co-simulation techniques. Two examples of a manipulator dynamics modelling were considered. One example with a considerably simplified mass spatial distribution, and another one with a mass distribution corresponding to a real commercial manipulator. The achieved analysis results confirmed that application of the co-simulation technique eases the use of complex models in analysis of manipulator dynamics with use of the general purpose computing environments.
\end{abstract}

Keywords: manipulators, dynamics, simulation, co-simulation

\section{TECHNIKI NUMERYCZNEJ SYMULACJI I KOSYMULACJI W ANALIZIE DYNAMIKI MANIPULATORÓW}

Analiza dynamiki manipulatorów z zastosowaniem uniwersalnych środowisk obliczeniowych daje możliwość petnego ksztattowania struktury modeli, algorytmu analizy oraz dostęp do wszystkich wyników czastkowych, jednak zwykle wymaga również wielu uproszczeń modelu. Alternatywnym podejściem jest wykorzystanie specjalizowanych pakietów oprogramowania, które daja możliwość stosowania bardziej złożonych modeli, lecz ograniczaja dostę do wyników pośrednich oraz zakres wprowadzania modyfikacji algorytmów analizy $i$ struktury modeli. Rozważania autorów dotyczq wykorzystania techniki kosymulacji w analizie dynamiki manipulatorów. Kosymulacja polega na zastosowaniu specjalizowanych pakietów oprogramowania do formutowania modelu dynamicznego, który jest nastepnie symulowany w uniwersalnym środowisku obliczeniowym we wspótpracy z specjalizowanym pakietem oprogramowania. Autorzy wykorzystali wspótprace środowiska Matlab/Simulink i pakietu oprogramowania MD ADAMS. W artykule przeprowadzono porównanie wyników symulacji i kosymulacji dynamiki manipulatorów w kontekście: zgodności, problemów zastosowania oraz przydatności dydaktycznej. Przedstawiono przykład analizy dynamiki ramienia manipulatora o uproszczonym rozktadzie masy i manipulatora o otwartym tańcuchu kinematycznym o rozkładzie masy odpowiadajacym manipulatorowi rzeczywistemu. Wyniki przeprowadzonych analiz potwierdzity, ze zastosowanie kosymulacji ułatwia wykorzystanie ztożonych modeli w analizie dynamiki manipulatorów za pomocq uniwersalnych środowisk obliczeniowych.

Stowa kluczowe: manipulatory, dynamika, symulacja, kosymulacja

\section{INTRODUCTION}

During last 60 years manipulating robots were gradually becoming common elements of manufacturing systems worldwide. Currently, service robots, used for instance in medicine, military, or exploration, are quite often equipped with a manipulator, too (IFR).

A robot constitutes a complex mechatronic system composed of a set of interconnected links, joints, driving systems, sensors and control devices. The properties of the system's elements as well as characteristics of their mutual cooperation determine robots' precision and productivity. These two contradictory properties considerably depend on robots' dynamic performance. A robot dynamic model is a quantitative (mathematical) description of the robot dynamic behaviour. Dynamic models are used at least in robot design, simulation testing and motion control synthesis (Lisowski et al. 2004).

The structure of a multilink manipulator dynamic model is considerably complex no matter what simplification assumptions are made. That is why, currently, the dynamic model is being built and represented numerically the most often with help of some software modelling tools. On the one hand, this eases and speeds up considerably the model formulation and application, but on the other hand, effective use of the computer aided engineering tools requires thorough understanding of robot dynamics. The engineering knowledge is the base for appropriate preparation of the substantial input data as well as for correct assessment of the obtained results quality. The skill of correct usage of appropriately selected software tools enhances effectiveness of the robot dynamics analysis.

* AGH University of Science and Technology, Faculty of Mechanical Engineering and Robotics, Department of Robotics and Mechatronics, Krakow, Poland, dbaran@agh.edu.pl, lisowski@agh.edu.pl 


\section{TECHNIQUES OF MODELLING ROBOT MANIPULATORS' DYNAMICS}

Principles of mechanics like Newton's law, Lagrange equations or the virtual work principle are the base for manipulator's dynamic model formulation (Fu et al.1987, Siciliano et al. 2009).

General Purpose Computing Environments - GPCEs are very efficient in teaching how to understand correctly robot dynamic behaviour (Baran 2009). Proper understanding of robot dynamics is necessary to acquire the skill of assessment of credibility of the simulation results basing on their appropriate interpretation. That is why GPCEs are commonly used for educational purpose. However generally, the use of GPCEs in everyday engineering practice is at least a bit inconvenient due to the necessity of time-consuming data preparation stage. The dynamic equations have to be formulated and the simulation input data like the mass inertia moments have to be determined by the users themselves.

GPCEs provide possibility to test various structures of the model and give good insight into the intermediate analysis results (Beucher and Weeks 2008). Application of GPCEs develops users' creativity. GPCEs are also suitable for research, mainly in case of testing new analysis methods and novel model structures. Such use of GPCEs is usually time consuming and requires advanced programming skills. Application of GPCEs has drawbacks like occasional numerical instability of the solution, and advantages like easy-to-use graphical interface as well as very easy 2D and 3D presentation of data, not mentioning wide data exchangeability with other software packages.

An example of popular GPCEs is Matlab/Simulink package (MATLAB, SIMULINK). An alternative approach to robot dynamic modelling is the application of the Specialized Software Packages (SSPs). Usually in practice of manipulators' dynamics modelling, the assumption of lumped masses is made, so the SSPs intended for analysis of kinematics and dynamics of assemblies (mulibody systems) are used. They possess capability to create the geometrical model of the multibody system under investigation, what assures precise description of a manipulator spatial mass distribution. Even higher precision is achieved by importing the geometry of the bodies from CAD software.

In case of application of the SSPs, the structure of the model is chosen from the set of the available ones. It is usually difficult, to implement own model structures or analysis algorithms. The dynamic equations of motion are formulated automatically by the software and often they cannot be presented to the user. Next, the packages are used in the mode of: enter the input data, accept and get results.

When SSPs are used by the experienced, advanced users, they are very effective in solving complex problems and running multistage analyses. Numerical stability of the used algorithms during simulation is high. Typical problems of the novice users are connected with preparation of the consistent, appropriate input data and assessment of results' credibility. Examples of the considered SSPs are: Adams (ADAMS),
RecurDyn (RECURDYN), SIMPACK (SIMPACK), and LMS VirtualLab (VIRTUALLAB).

There is possibility to combine the two described above modelling techniques. This approach is called co-simulation - the use of a set of cooperating software packages with the aim to simulate the model of the system under investigation (Brezina et al. 2011).

In case of dynamic modelling the co-simulation technique usually consists in application of a SSP to formulation of the dynamic model. Then, the model is implemented as a piece of code and transferred to a GPCE. Next, the model is simulated with use of the GPCE. Cooperation of the GPCE and the SSP requires concurrent running of the both software packages during co-simulation.

The co-simulation may be carried out for example by cooperation of Matlab/Simulink GPCE and Adams SSP (YiBo et al. 2011) or Matlab/Simulink GPCE and RecurDyn SSP (Yan-Shen Wang et al. 2011) or Matlab/Simulink GPCE and LMS VirtualLab (Manka et al. 2009).

An example of co-simulation of a planar closed loop mechanism's dynamics and control is presented in (Affi and Romdhane 2005). Co-simulation of a manipulator kinematics is described in (Cheranghpour et al. 2011). In (Yan-Shen Wang et al. 2011) there is presented an example of co-simulation of dynamics of a manipulator motion along a planned trajectory. Authors of (Brezina et al. 2011) show application of co-simulation in virtual prototyping (multiple development cycles) of a manipulator for the purpose of joined analysis of a set of subsystems. The analysis dealt with the system topology, kinematics, dynamics and motion control. Application of co-simulation in seam tracking analysis and development is discussed in (YiBo et al. 2011).

\section{PROBLEM FORMULATION}

Procedure of formulation of dynamic models covers selection of the model structure and determination of the model parameters. The authors restricted the following analysis to the model parameters concerning the manipulator links' mass spatial distribution for assumed structure of the dynamic model. The rigid links and joints were considered and the friction was neglected. Implicit character of dynamic models produced by SSPs makes reconstruction of their friction components for use in GPCEs difficult. It is not easy to reproduce such components equivalently in a model used in simulation (GPCE). Lack of the equivalence might cause differences between results of simulation and co-simulation. In the opinion of the authors the above mentioned assumptions did not affect the achieved results and the drawn conclusions.

When a high number of non-standard numerical simulations of dynamic behaviour of an object of complex spatial mass distribution pattern has to be carried out, application of GPCEs involves high number of repetitions of preparation of the simulation input data and a time consuming definition of the spatial mass distribution of a manipulator links as well 
as of integrated elements like: motors, gearboxes, couplings, sensors, cabling, etc.

On the other hand, application of SSPs limits possibility to implement non-standard analysis algorithms, what is much easier with use of GPCEs.

In this paper, the authors addressed the problem if application of the co-simulation technique, that makes use of both GPCE and SSP tools, is an effective compromise providing both:

- fast formulation of the model of the object that has a com plex mass distribution pattern,

- easiness of implementation and modification of the analysis algorithms.

In the first stage of the carried out investigations, a manipulator dynamic model that had considerably simplified spatial mass distribution was used. So, the dynamic model could be prepared in Matlab (GPCE) very fast. The corresponding dynamic model was also prepared in Adams (SSP) and then transferred to Matlab to make running of the co-simulation procedure possible. Next, the simulation and co-simulation procedures were compared in aspects of: consistence of results and didactic usefulness.

The second stage aimed at presentation of application of the co-simulation procedure to a manipulator of more complex mass distribution pattern.

\section{ANALYSIS OF APPLICATION \\ OF THE CO-SIMULATION TECHNIQUE IN MANIPULATOR DYNAMIC ANALYSIS}

This chapter reports the authors' investigation into manipulator dynamics modelling. The analysis consisted of the 2 following parts:

- comparison of results of simulation and co-simulation of the equivalent simplified dynamic models of a manipulator arm,

- a case-study of co-simulation of motion dynamics of a manipulator with more complex mass spatial distribution pattern.

Spatial mass distribution is represented in a manipulator dynamic model directly by the inertia tensors or with use of the pseudo-inertia matrices (Fu et al. 1987).

Usually, the mass of manipulators' structural elements is distributed spatially almost symmetrically. This symmetry constitutes a base for simplification of description of the spatial mass distribution that leads to considerably less complex form of the dynamic model of a manipulator. Assumption of neglecting a slight asymmetry of the spatial mass distribution leads to common application of a model of an infinitely thin rod for manipulator links. It is quite a good approximation of mass distribution for a slim hollow links, but its use for links that cannot be considered to be slim, even in case of the thin wall hollow ones, is not recommended, not only due to neglecting of the inertia moment about the link's longitudinal axis, but also as a result of considerable underestimation of inertia mo- ments about axes perpendicular to the link's longitudinal axis. It should be noted that asymmetrical placement of integrated elements (components of driving systems) changes not only the values of a link's inertia tensor, but also the location of a link's centre of mass.

The analysis presented in the next subsection is based on a manipulator possessing a simple, symmetrical mass distribution pattern.

\subsection{Comparison of results of simulation and co-simulation of a manipulator dynamics}

To investigate the co-simulation technique the simulation and the co-simulation of the equivalent dynamic models of a manipulator were carried out. Figure 1 presents the assumed algorithm of the analysis.

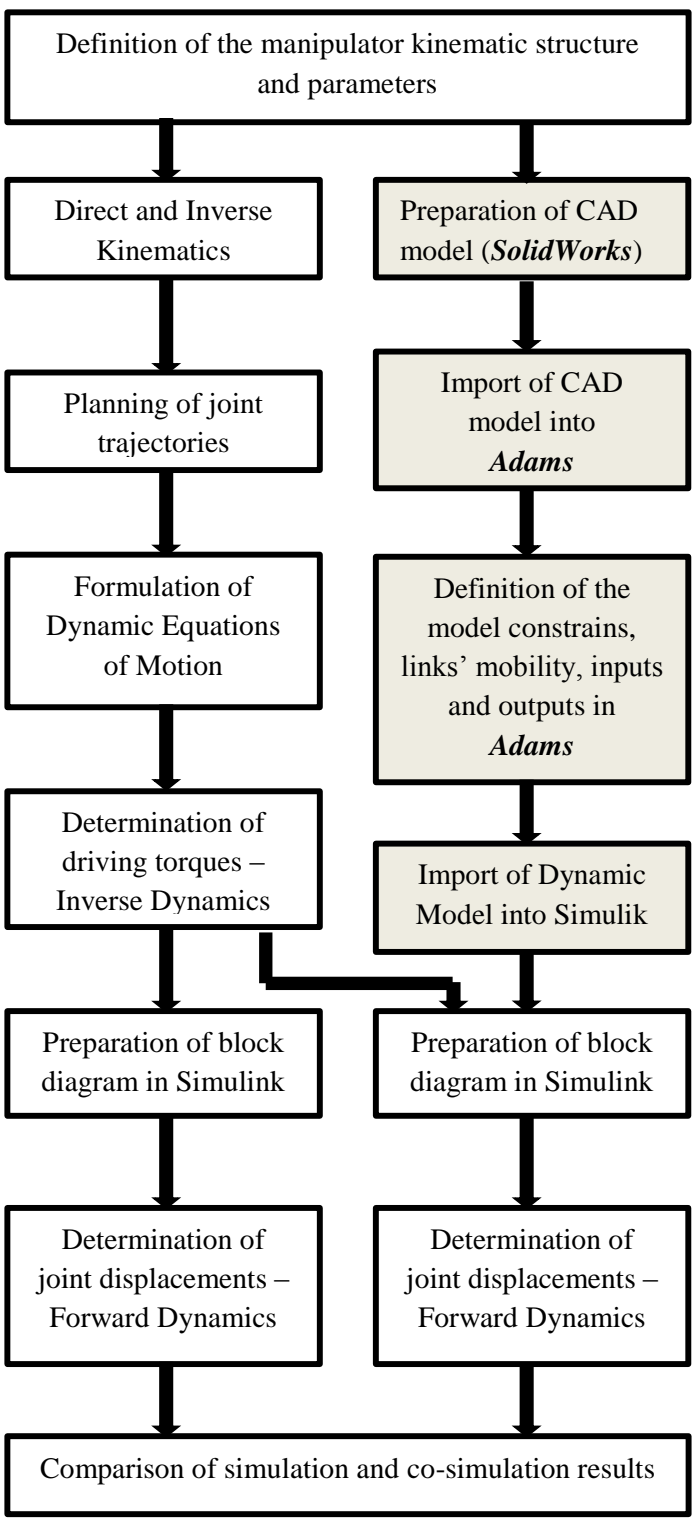

Fig. 1. Diagram of procedure of comparison of simulation and co-simulation techniques 
The dynamic model of an exemplary anthropomorphic manipulator arm (of RRR-type) was prepared concurrently with use of Matlab/Simulink (GPCE) and Adams (SSP). The homogeneous transformation was used for formulation of the manipulator's kinematic model (fig. 2).

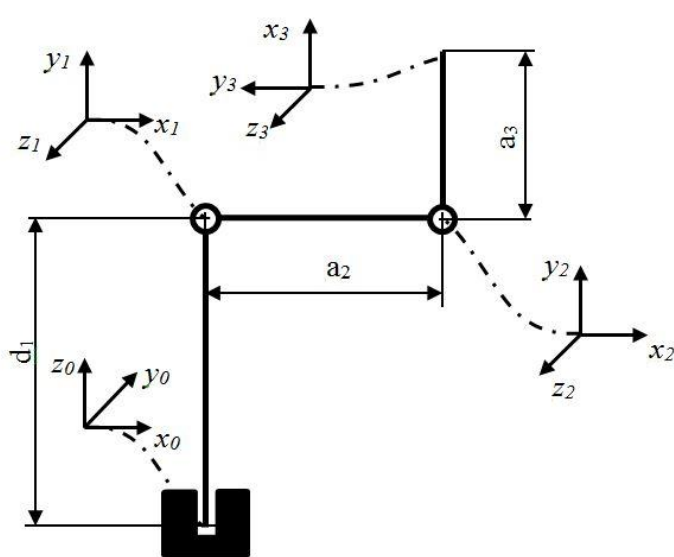

Fig. 2. Kinematic model of the RRR manipulator

Parameters of the manipulator's kinematic model (Fu et al. 1987) are listed in table 1.

Table 1

Parameters of kinematic model of the RRR manipulator

\begin{tabular}{|c|c|c|c|c|}
\hline Link No. & $\theta$ & $d$ & $a$ & $\alpha$ \\
\hline 1 & $\theta_{1}$ & $d_{1}$ & 0 & $90^{\circ}$ \\
\hline 2 & $\theta_{2}$ & 0 & $a_{2}$ & 0 \\
\hline 3 & $\theta_{3}+90^{\circ}$ & 0 & $a_{3}$ & 0 \\
\hline
\end{tabular}

The fifth degree polynomial spline functions were used to plan 9 segment joint trajectories of motion (Fu et al., 1987) corresponding to a pick and place operation.

The hollow, prismatic, circular cross-section rod was assumed as the type of model of the spatial mass distribution of each manipulator link. Masses of the consequent links were set to be $m_{1}=1.53 \mathrm{~kg}, m_{2}=1.84 \mathrm{~kg}$ and $m_{3}=1.22 \mathrm{~kg}$.

Next, the dynamic equations of motion (DEoMs) were formulated with the use of symbolic computation functionality of Matlab. The prepared trajectories were substituted to the DEoMs to get time histories of driving torques that in turn became inputs to forward dynamics in both cases of simulation and co-simulation. The Simulink diagram was prepared to solve numerically the forward dynamics problem. In order to run the simulation (Matlab/Simulink) the integration method, type (constant or variable) and size of time step, and type of input signals (continuous or discrete) had to be set (Karris 2006).

Preparation of co-simulation started with formulation of the geometrical model of links carried out in SolidWorks. Next, the geometry of links was transferred to Adams in a parasolid ('*.X_t' format) file. The important issue was the use of the consistent definition of the co-ordinate frames in SolidWorks and Adams in order to get proper import of the links' geometry to Adams. After the transfer, the manipulator joints were defined by introduction of geometrical constraints for pairs of the adjacent manipulator links.

The DEoMs equations were formulated in Adams in the implicit form and then transferred to Matlab/Simulink via a parasolid type file. The prepared Simulink block diagram of co-simulation is presented in figure 3 .

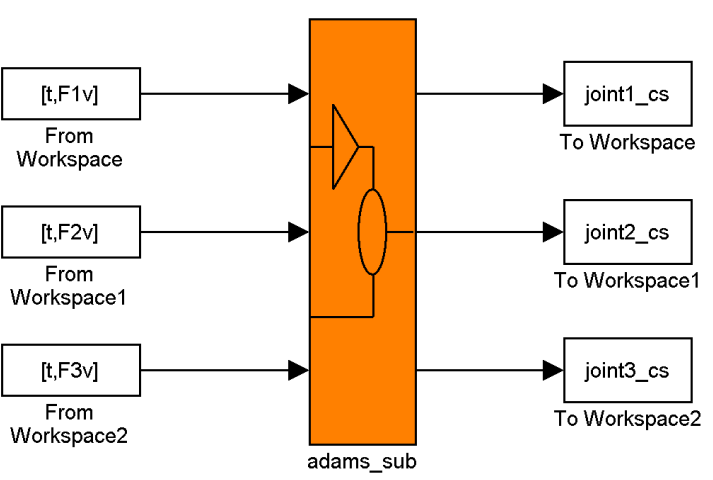

Fig. 3. The Simulink block diagram of co-simulation

Next, the parameters of the created Simulink block 'adams_sub' (Adams Plant) like: the type of solver (the solver type selections influences the time of the simulation), the simulation mode and the communication interval were set (fig. 4).

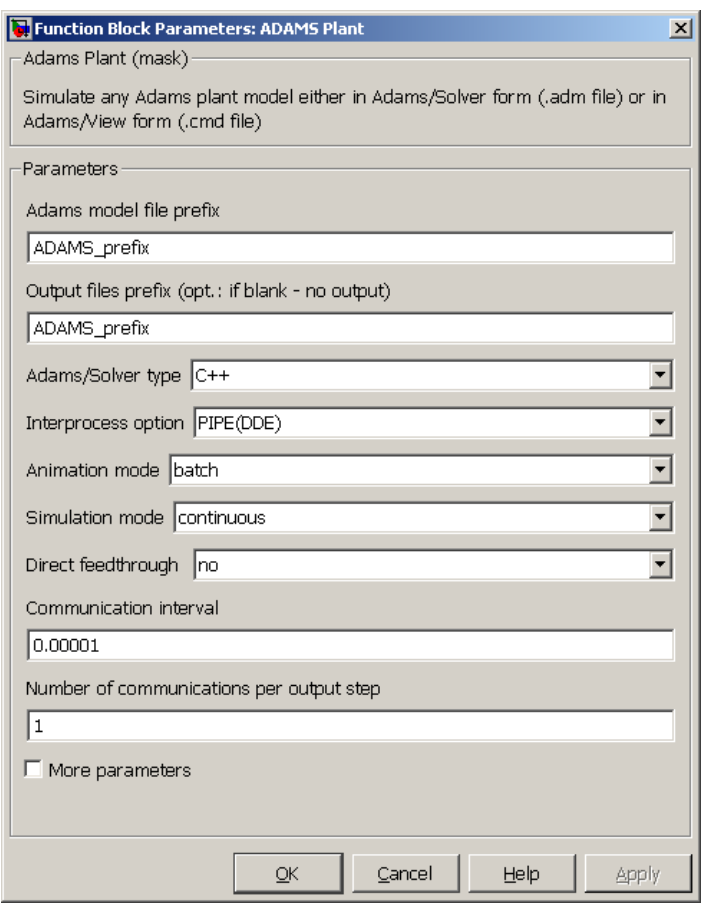

Fig. 4. Settings of Adams Plant parameters

The results of the carried out simulation and co-simulation were compared with the planned joint trajectories. In case of setting parameters of the 'From Workspace' block (comp. fig. 3) the best consistence of the achieved displacements' time histories and the planned joint trajectories was obtained in case of using the sample time inherited from Adams and the inter- 
polated driving torques. The difference between the planned trajectories and their numerical approximations in both the simulation and co-simulation cases did not exceed 1.2 10-4 rad. Such the value approximately corresponds to the order of magnitude of the high positioning repeatability of modern industrial robots.

The difference between displacement time histories obtained as a result of simulation and co-simulation was presented in figure 5 for 3 joints of the exemplary manipulator.
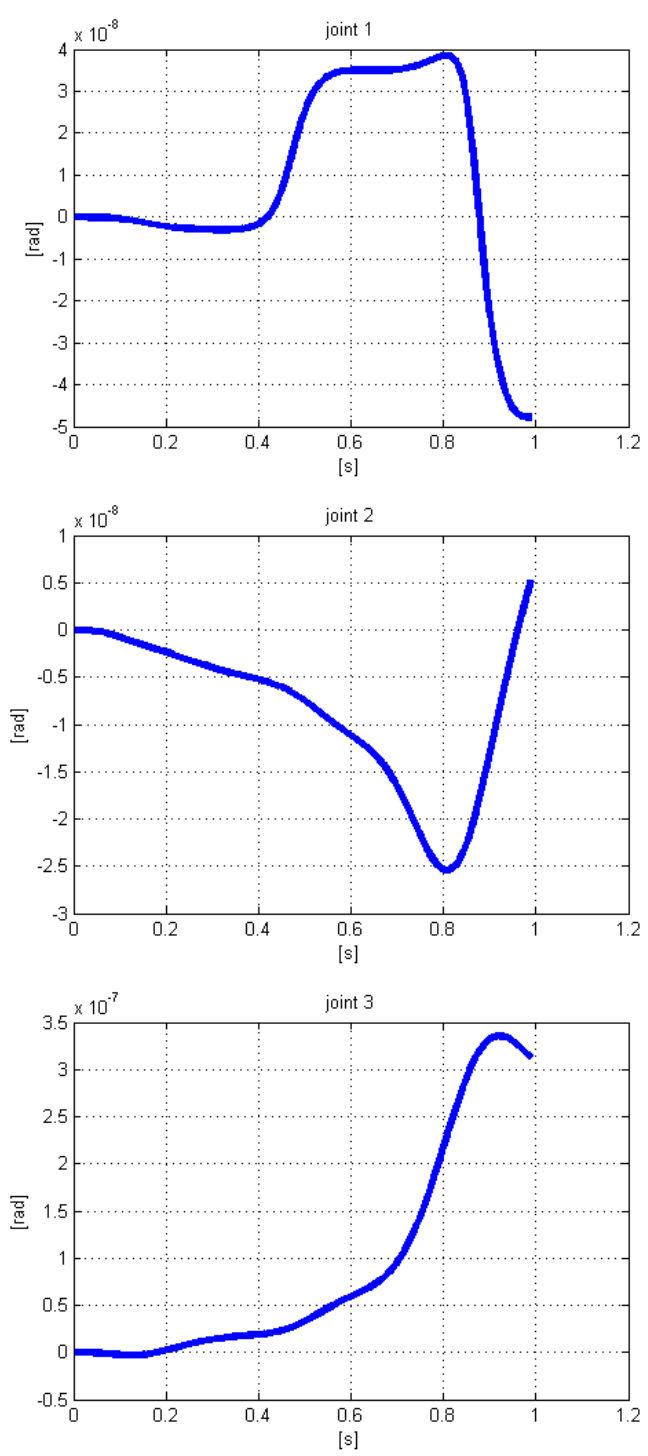

Fig. 5. The difference between joint displacement obtained in simulation and co-simulation

The results of the above described analysis showed that the use of procedure of the simulation and the procedure of co-simulation led to the approximately the same result which was consistent with the expected one (the planned joint motion trajectories).

The simulation time was approximately 1 minute, what was at least 12 times shorter than the time corresponding to co-simulation, so the assumed simple links' spatial mass distribution and availability of a tool used for formulation of DEoMs made application of the simulation technique more effective than use of the co-simulation technique in the described case study. When the problem of use of the simulation and the co-simulation techniques for educational purpose is concerned it should be noted that the use of co-simulation develops skills of use of dedicated software tools and techniques of data exchange between various tools.

In the considered case, the lack of possibility to analyze the form of DEoMs proved to be the drawback of use of cosimulation for educational purpose.

\subsection{Example of application of the co-simulation technique}

The reported below example of application of co-simulation technique dealt with analysis of the SCARA type Adept Cobra 800 manipulator kinematics and dynamics.

The outline of the analysis corresponded to the one described in the previous subsection. The analysis was composed of 3 successive stages: kinematic modeling and joint trajectory planning, determination of joint torques (inverse dynamics), and then calculation of joint displacements (forward dynamics) for the determined joint torques. The diagram of the carried out analysis was presented in figure 6.

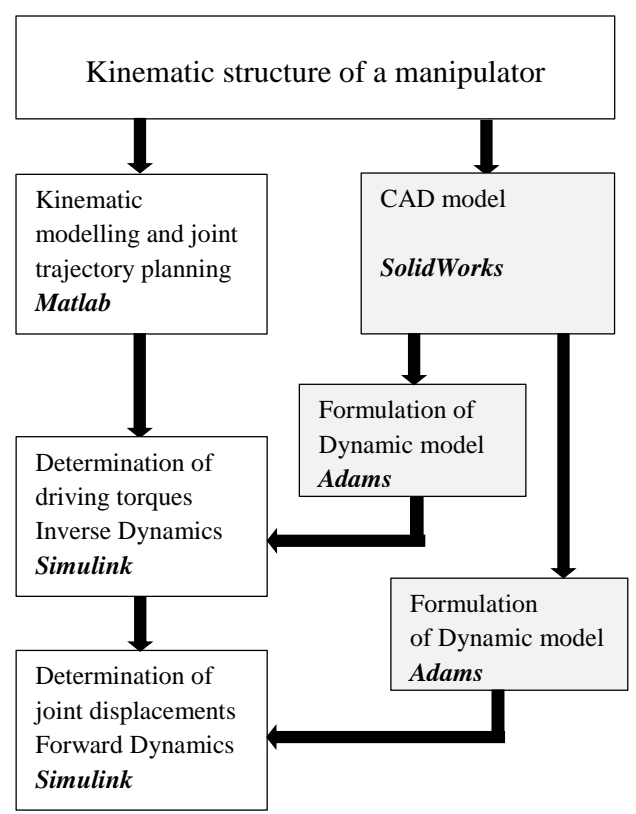

Fig. 6. Diagram of co-simulation of dynamics of a manipulator

The GPCE (Matlab) was used to set the flow of the analysis and to perform one non-standard analysis - kinematic modeling and joint trajectory planning, as well as two successive numerical co-simulations. The spatial 13 segment trajectory corresponded to one cycle of a pick and place operation of the considered manipulator. The planned end-effector path is presented in figure 7.

The SSP tools (SolidWorks and Adams) were used for standard analyses - determination of link's inertia tensors, as well as formulation of direct and inverse dynamic models of the manipulator. Then, Adams was used during co-simulation. 
The mentioned standard analyses would be very complex to carry out with use of a GPCE tool in case when no dedicated procedure was available. Preparation of such the procedure would be very time-consuming. These justified the application of the co-simulation method in the considered case.

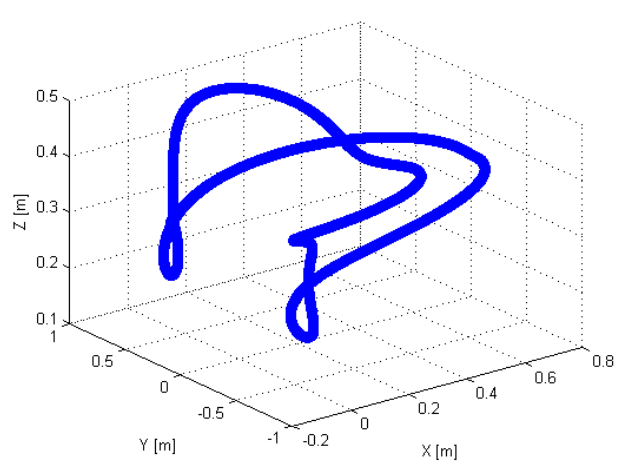

Fig. 7. The planned path of the pick and place operation used during simulation

Next, inertial parameters of the dynamic model were determined for an approximate CAD model of the manipulator downloaded from (ADEPT). An overview of the model showing links, joints and integrated elements is presented in figure 8.

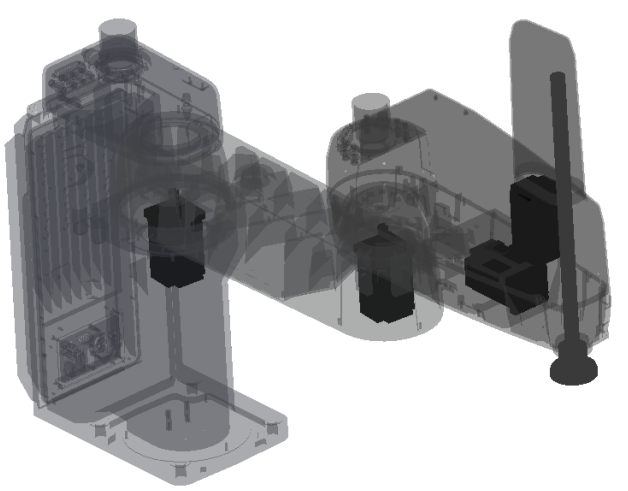

Fig. 8. Overview of the used CAD model of the Adept Cobra 800 manipulator

Both inverse and forward models were transferred to Matlab/Simulink as Adams Plant Simulink blocks and used in 2 successive steps of the co-simulation analysis.

The results of integration of the DEoMs differed from the planned trajectories. Figure 9 presents the differences for 4 manipulator's joints.

The differences between the planned generalized joint displacements and the ones achieved with use of the SSP were as high as 0.02 rad (joints No. 1, 2 and 4) and $0.04 \mathrm{~mm}$ (joint No. 3). Consistency of results of the forward dynamics co-simulation, when compared to the planned trajectories was considerably worse than the one reported in the previous subsection. It was found that the differences could be varied slightly by adjusting the co-simulation procedure parameters in Adams.
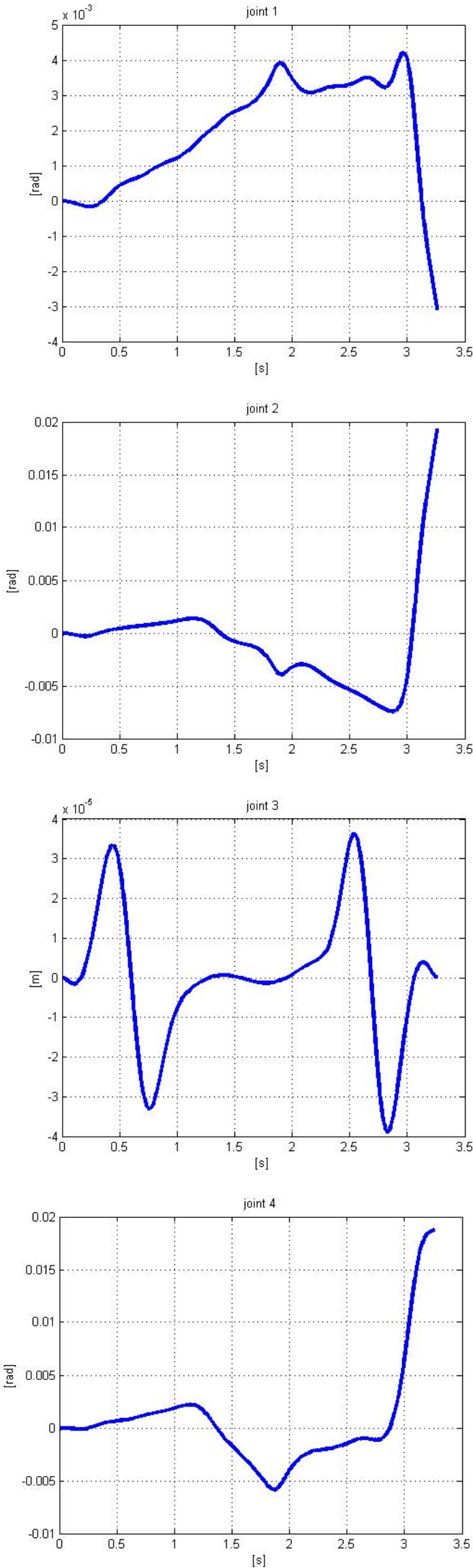

Fig. 9. The difference between the planned and the co-simulated (inverse $\rightarrow$ forward dynamics) 4 joint trajectories of Adept Cobra 800 manipulator 
It should be noted that the used manipulator spatial mass distribution model contained only selected, present in the downloaded file, robot components, and the model parts' material properties had to be assumed for the analysis purpose (no data were available). So the obtained results characterized the considered manipulator only qualitatively (approximately). The presented example showed how the idea of co-simulation could be used to assure effectiveness of analysis of kinematics and dynamics of a manipulator of complex mass distribution pattern. It was found also that experience in selection of parameters influences quality of the co-simulation results.

\section{SUMMARY}

The paper presented examples of application of co-simulation technique in analysis of dynamics of robotic manipulators. The application of the SSP tool assured fast formulation of the dynamic model of the object of a complex mass distribution pattern. The use of the GPCE tool provided possibility to implement the assumed analysis algorithm (kinematics and trajectory planning followed first by invers dynamics and finally by forward dynamics) and carry out its nonstandard part (kinematics and trajectory planning). It was showed on the example of solution of the forward dynamics problem that use procedure of the simulation and the procedure of co-simulation might lead to almost the same result.

In the first considered analysis case comprising comparison of simulation and co-simulation of forward dynamics, the difference between the planned joint trajectories and the ones obtained in the result of numerical simulation/co-simulation was comparable to robots' positioning repeatability, so care must be taken during simulation carried out with the aim of analysis of robots' positioning errors.

In the second considered case comprising co-simulation of inverse dynamics followed by co-simulation of forward dynamics, the magnitude of the obtained differences was higher. It slightly depended on the selected values of co-simulation procedure parameters.

Basing on the results of the simulation and co-simulation case studies conducted during preparation of this paper the authors formulated the following general remarks. The cosimulation is more useful for engineering applications, where the user is focused on getting results quickly and the spatial mass distribution of a manipulator is complex.

The use of co-simulation by unskilled users is recommended for educational purpose (to get acquaintant with professional simulation tools and to learn practical details of methods of cooperation of various software tools), but might lead to only approximate results partly due to insufficient experience of such the users.

On the other hand, the pure simulation technique is recommended for teaching purpose because it helps the novice students to understand the physics of the modelled system. In the case of more advanced users application of GPCE is suggested for development of complex algorithm, as it provides easy access to intermediate results as well as to model structure, and values of model's parameters.

\section{Acknowledgements}

The research reported in this paper has been financed from the state budget for science.

\section{References}

Affi Z., Romdhane L. 2005, ADAMS/Simulink Interface for Dynamic Modeling and Control of Closed Loop Systems. WSEAS Int. Conf. on Automatic Control, Modelling and Simulation, Prague, pp. 493-397.

Baran D. 2009, Formulation of numerical and symbolic procedures aiding modelling of kinematics and dynamics of manipulating robots (in Polish). Master Thesis at AGH University Science and Technology, Krakow, Poland.

Beucher O., Weeks M. 2008, Introduction to MATLAB \& SIMULINK: A Project Approach. Infinity Science Press LLC.

Brezina T., Hadas Z., Vetiska J. 2011, Using of Co-simulation ADAMS SIMULINK for Development of Mechatronic Systems. IEEE Mechatronika, 14th Int. Symposium, Trencianske Teplice, pp. 59-64.

Cheranghpour F., Vaezi M., Jazeh H.E.S., Moosavian S.A.A., 2011, Dynamic Modelling and Kinematic Simulation of Stäubli TX40 Robot Using MATLAB/ADAMS Co-simulation. IEEE Int. Conf. on Mechatronics (ICM), Istanbul, pp. 386-391.

Fu K.S, González R., Lee C.S.G. 1987, Robotics: Control, Sensing, Vision and Intelligence. McGraw-Hill Book Company.

Karris S.T. 2006, Introduction to Simulink ${ }^{\circledR}$ with Engineering Application. Orchard Publications.

Lisowski W. (Editor) 2004, Introduction to Robotics. Uczelniane Wydawnictwa Naukowo-Dydaktyczne AGH

Mańka M., Giner D.M., Kang J. 2009, Co-simulations of motorcycle-rider system in road behaviour simulations. ASME 2009 Design Engineering Technical Conferences \& Computers and Information in Engineering Conference (DETC 2009), San Diego, California, USA.

Yan-Shen Wang, Yu-Xian Gai, and Ping-Chun Xie 2011, Dynamics cosimulation of a type of spot welding robot by RecurDyn and Simulink. Consumer Electronics, Communications and Networks (CECNet), Int. Conf. on, pp. 4934-4937.

Siciliano B., Sciaviccio L., Villani L., Oriolo G. 2009, Robotics: Modelling, Planning and Control. Springer

YiBo D., Hua Z., GuoHong M. 2011, A Co-simulation of Seam Tracking System Based on ADAMS and SIMULINK. Mechanic Automation and Control Engineering (MACE) 2011 Second Int. Conference on, Hohhot, pp. $8-11$.

ADAMS at www.mscsof tware.com/MSCSoftware MD Adams.

ADEPT at http://www. adept.com/products/robots/scara/cobrai600/downloads, Adept .

IFR at www. ifr.org International Federation of Robotics

MATLAB at www.mathworks.com/help/techdoc/ The Mathworks Inc. MATLAB ${ }^{\circledR}$ Software.

RECURDYN at www.recurdyn.de/index.php FunctionBay Inc., RecurDyn.

SIMULINK at www . mathworks . com/help/toolbox/simulink/ The Mathworks Inc. Simulink User's Guide.

SIMPACK at www. simpack. com SIMPACK AG, SIMPACK.

VIRTUALLAB at www.Imsintl.com/vituallab LMS Engineering Innovation. 